\title{
Enhancing positive emotions via positive interpersonal communication: an unexplored avenue towards well-being of mankind
}

\begin{abstract}
Interpersonal Communication is at the root of human existence itself. It is through communication that interpersonal relationships are formed, managed and dissolved (when the occasion arises). The quality of relationship - positivity/negativity is one of the most powerful psychosocial predictors of one's physical and mental health outcomes.

Positive emotions-experienced by an individual during, or subsequently to positive communication with another person produces a pleasant state of body and mind accompanied by enhanced immune system functioning, undoing of negative cardiovascular incidents, and building of physiological, psychological and social resources for coping with stressful life challenges and contribute to physical and mental health, happiness and more successful performance.

Negative emotions also have an intuitively adaptive value. In an instant, they narrow other thought action repertoire to those of fight or flight that promote our survival in life threatening situations. They produce a downward spiral of ill-being unlike positive emotions which create on upward spiral of wellbeing. Such grossly opposite positions of them in human beings is due to "functional asymmetry" of our two hemispheres of brain - the right one sub serving negative emotions, activating specific neuroendocrine channels stimulating an unpleasant state of body and mind; and the left one sub serving positive emotions and activation of different neuroendocrine channels creating a pleasant state of body and mind.

Even amidst overwhelming negativity in almost all dimensions of human life in the present era, a ray of hope is that relentless attempt to be a good communicator generating positive emotions in self and others can yield the desired result. It can go a long way out by cultivating the habit of being a good communicator. This is a matter of attitude and not money - caring words, listening with all attention, using a calm tone of voice, looking in the eyes, a smile and a genuine concern for wellbeing of the communicatee are all what are needed.
\end{abstract}

Keywords: positive emotions, positive communication, well-being of mankind
Volume 7 Issue 4 - 2017

\section{Indrani Mukherjee}

Department of Applied Psychology, Rash Behari Sikshya Prangan Calcutta University Colleges of Science, India

Correspondence: Indrani Mukherjee, Professor, Department of Applied Psychology, Rash Behari Sikshya Prangan Calcutta University Colleges of Science, 92 A. P. C. Road, Kolkata 700009, India, Email mrs.indranimukherjee@gmail.com

Received: November 24, 2016 | Published: March 22, 2017

\section{Introduction}

In Indian-Bengali community the elderlies, if occasion arises, bless the younger ones by touching the head and uttering "Be healthy, be happy and live long". It reflects the general belief, intricately interwoven with culture of this land, that being healthy, being happy and living long are the most coveted goals in human life. Perhaps the same sort of wishes for self and others - near and dear - existed and exists in human mind across generations and across different cultures globally. In the present article - Health, Happiness and Longevity have been considered as three components of wellbeing of mankind.

Kuppens \& Diener ${ }^{1}$ noted in their article an observation by William James, ${ }^{2}$ more than a century ago (in1902) that being happy is the universal secret motive of most people which guide what they do and what they are willing to endure. The authors labeled pursuit of happiness as one eternal human quest. Happiness is viewed almost synonymous with and emanating from a sense of Subjective WellBeing (SWB)** which has two aspects: a cognitive judgment that life, so far, has been satisfactory, and an emotional component comprising of frequent, small positive emotions and an absence or low level of negative emotions. ${ }^{3}$
The second and third aspects contribute to emotional Wellbeing, an important facet of SWB. ${ }^{4}$ Yulimaz \& Arsalon $^{5}$ found positive relationship between SWB and positive emotions and negative relationship between negative emotions and SWB. These results showed that increasing positive emotions of individuals and.

***"Subjective Well-being" and "Well-being" are not to be confused with each other. The latter includes Health and Longevity besides happiness. "SWB" would be used interchangeably with "happiness" in this article.

Decreasing the negative emotions will affect their happiness or subjective wellbeing positively. Not only that positive and negative emotions act as mediators of relationship between Trait Emotional Intelligence and Life Satisfaction. The indirect effect of Trait E. I. on life satisfaction via positive affects was reportedly stronger than that via negative affects. ${ }^{6}$ The author here feels that probably a very rich source of positive emotions in daily life is that imbued in interpersonal communications as experienced by any individual while talking with other. $^{7}$

Communication is one of the most basic elements in human functioning because positive and effective communication is the 
cornerstone of strong and healthy interpersonal relationship. The reverse is also very much true. The quality of communication has a direct impact on quality of relationship. The latters are important because they affect how people feel about themselves. ${ }^{8}$ Because, through personal relationships, we may find our most profound experiences of security and anxiety, power and impotence, unity and separateness. ${ }^{9}$

Euripedes ${ }^{10}$ pointed out the close link between psychological problems and social relations, which got supported by later researches in the field. ${ }^{11}$ Emotionally satisfying relationship may gratify basic needs, fulfill fundamental values, meet developmental tasks; further instrumental pursuits, appease environmental demands or merely feel up free times. One point is clear, good interpersonal skills combined with good interpersonal problem solving skill and high social selfefficacy constitute a good coping behavior by which one identifies effective coping response for specific problematic interpersonal situation, ${ }^{12}$ creating emotional positivity in interpersonal situation in both the communicator and the communicatee.

\section{Positive and negative emotions in relation to longevity}

Frederickson ${ }^{13}$ studied the special value of positive emotions. She reported the finding of an empirical study on the positive emotions as experienced by nuns in early life and their later longevity. Reading the nuns' biographic sketches and scoring them for positive emotional content, i.e. recording of happiness, interest, love and hope, revealed that those who expressed most positive emotions lived upto ten years longer than those who expressed the fewest. According to Frederickson these findings along with those of several other studies, provide support to the contention that people who feel good, live longer.

Diener \& $\mathrm{Chan}^{14}$ reviewed nineteen longitudinal studies linking SWB or happiness and mortality in normal population and concluded that high SWB causes better health and longevity. They went on further by saying that "Combined with experimental human and animal research as well as naturalistic studies of changes of subjective wellbeing and physiological processes over time, the case that subjective well-being influences health and longevity in healthy populations is compelling." However, the claim that subjective wellbeing lengthens the lives of those with certain diseases, e.g. Cancer remains controversial. "There remains no doubt that positive feeling predict longevity and health beyond negative feelings. But intensely aroused or manic positive affect is detrimental to health."

In today's world one of the most common problem is the area of interpersonal relationship which is intrinsically woven with the issue of Interpersonal communication. Because communication is the process vehicle through which relationship are formed, managed and when occasion arises, gets dissolved. ${ }^{15}$ And in our everyday life positive and negative affects are being generated while relating to others through communication. The purpose of this article is to show some ray of hope in minimizing negative and accentuating positive emotions through communication - a fundamentally important adaptive behaviour.

Henderson ${ }^{16}$ argued that inability to satisfy a need for affectively positive interactions with others leads to psychiatric and even medical morbidity which if not intervened properly, may kill the individual. Between the starting point and the end point lie innumerable sufferings of the individuals. The accompanying distress of the unhappy persons, irrespective of whether his life is shortened by killing diseases or suicides, his unproductively and inability to serve self and society in a positive fashion is a kind of loss of national human resources. Thus absence and/or disruption of positively satisfying relationships not only compound clinical disturbances or play some part in their etiology or may simply lead the individual to deviant or abnormal ways of satisfying those functions, that healthy personal relationship normally fulfill. All these would have been impossible to occur in absence of interpersonal communication.

\section{Interpersonal communication versus positive and negative emotions}

One cannot live in a void -devoid of human contacts. Each and every human situation is interwoven either interpersonal and/or interpersonal communication. Both of them need to be positively meaningful. Negative communication is undesirable, leading to feeling of being misunderstood, frustration, dissatisfaction, loneliness, agony and trauma of being discarded by (significant) others, perception of lack of confidants and so on - if continuous, leads to death by disease/ suicides.

It becomes easier to visualize now that somehow positive emotions generated by positive communications determine not only the quality and quantity of relationships, but simultaneously it acts as a casual factor in promoting health and happiness. ${ }^{17,18}$ A state of Subjective Wellbeing reached via the root of experiencing positive emotions can combat mortality in many diseases. Effective and positively meaningful communication leads to a positive emotion known as "Perception of Communication Satisfaction" or PCS. ${ }^{19}$ It promotes physical and mental health ${ }^{6,20,21}$ and provides an experience of what is known as "Personality Support". ${ }^{22}$ It creates a sense of subjective wellbeing. If does so by creating a "Supportive Social Climate"23 characterized by acceptance, interest, reduced suspicion, increased tolerance, and increased stability.

\section{Anxiety decreases and it causes two important personality changes}

i. People begin to achieve a heightened feeling of personal adequacy, i.e. improved self-image; and

ii. People achieve acceptance of their own negative emotions and feelings of internal conflict, hence experience less anxiety,

iii. Besides, "General Adaptation Energy" 24 is more available for constructive and socially productive endeavors. And all of them occur when people give positive messages to self after perceiving others' interactions with themselves. Therefore, it is easy to see now that human beings cannot live healthily in a void which is devoid of positively meaningful human contacts

Relationship positivity and negativity, not only are generated by positive or negative emotions respectively, but they themselves also generate further positive and negative emotions. However, it would be appropriate here to mention that on the one hand emotional processes are likely to play an important role in the association between quality and quantity of relationships and physical and mental health, longevity and happiness on the other.

To understand the underlying mechanism, it is essential to draw now the link between how do positive communication and hence, pleasant feelings help people live longer and better.

Positives unlike negative emotions are a little harder to study. They are comparatively few and relatively undifferentiated - joy, amusement and serenity are not easily distinguished from one another. Anger, fear and sadness are distinctly different kinds of 
experience. Various physical components of emotional expression similarly reveal a lack of differentiation for the positive emotions. Angry, sad or fearful faces can be readily identified. In contrast facial expressions for positive emotions have no unique signal values, all share a smile. A similar distinction is evident in the response of the Autonomic Nervous System (ANS) to the expressions of emotions. While anger, fear and sadness each elicit distinct responses in the Autonomic Nervous System the positive emotions appeared to have no distinguishable autonomic responses. The negative emotions have an intuitively obvious adaptive value. In an instant they narrow our thought action repertoire to those responses (Fight/Flight) that best promoted our ancestors' survival in life threatening situation. In this view, negative emotions are efficient solutions to recurrent problems that our ancestors faced from the evolutionary perspective. On the other hand, joy, serenity and gratitude do not seem as useful as fear, anger and disgust. Perhaps positive emotions merely signaled the absence of threats. Researchers, through the last two decades indicated that they enhance immune system functioning and build psychological and social resources for coping with stressful life challenges which contribute to mental health and more successful performance. People can actively cultivate positive emotions to increase their wellbeing and coping skills. ${ }^{25}$

Instead of solving problems of immediate survival, positive emotions solve problem concerning personal growth and development. Experiencing a positive emotion leads to states of mind and behaviour that indirectly prepare an individual for later and hard times. Just as negative emotion provided strong evolutionary advantage for our ancestors by promoting self-protective responses to aversive circumstances, positive emotions helped them and help us to explore and understand our environments. The beneficial effects of positive emotion may be due to the fact that in part it drives us to explore, understand and develop ourselves and our worlds changing ours's as well as others' lives towards better. Thus, both negative and positive emotions are psychologically and adaptively worthy of themselves.

In the above context, Fredrickson ${ }^{26}$ proposed her "Broaden and Build" theory which provides an overview of how positive emotions help build physical, psychological and social resources. Her theory has received considerable attention from the scientific community as the first theory describing potential values of positives emotions. She proposed the "positive emotion broadens an individual's momentary mindset and by doing so helps to build enduring personal resources", and she has empirically proven it also. A simple paradigm next shown (Figure 1) explains how experience of positive emotion gives rise to its subsequent stages building upon one another.

Source: Fredrickson BL 21 "Positive Emotions". In: Snyder \& Lopez (Eds.), Handbook of Positive Psychology, Oxford University Press, NY, USA, pp. 120-134.

Now looking at the negatives, Baumgardner \& Crothers $^{25}$ have put it in the following way. Depression - a negative mood - can produce a downward spiral of ill-being and increasing negative mood of pessimistic thinking. Negative mood causes more pessimism and more pessimism causes intensified negative mood. Conversely Fredrickson proposed the positive emotions may create an upward spiral of wellbeing. She further reported that research has shown that positive emotions broadens the outlook, offsets negative emotions, enhance resilience and improves emotional wellbeing. A broader outlook and increased resilience may in turn increase the experience of positive emotions and so on. In short, positive may help build physical resources for fighting disease, due to enhanced immunity and undoing the negative cardiovascular. Incidents ${ }^{18}$; building our individual psychological resources (in the form of support from others) which are also important in dealing with nearly all challenges in life.

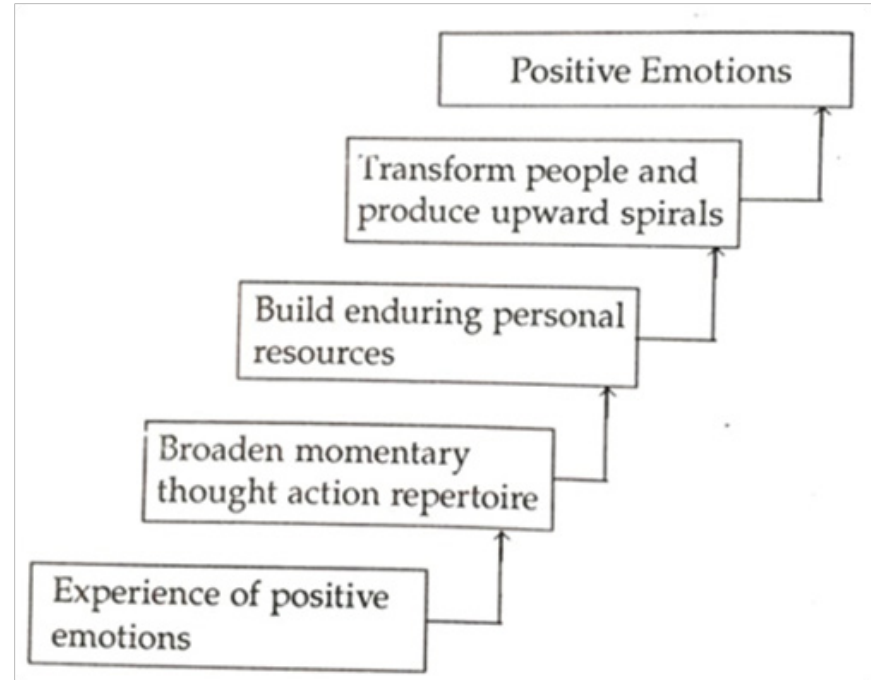

Figure I Upward Spirals of well-being as a consequence of experiencing positive emotions.

Positive emotions are at the base of four positive contents - Hope, Resilience, (Self) Efficacy and Optimism - of the most important and current construct of positive psychology. It is known as Psychological Capital (PsyCap) having positive impact on attitudes, behavior and performance (enhancing Happiness) ${ }^{27}$

Positive emotion enhances resilience or positive adaptation in the midst of adversities. Resilient people use positive emotions to bounce back from negative emotional experiences, can flexibly adapt to changing demands in stressful situations. They proactively cultivate their positive emotionality by strategically eliciting humour, by the relaxation techniques, by optimistic thinking. In crises, resilient people are buffered from depression by positive emotions. As positive emotions are subtle and feeling experiences, according to Fokman, ${ }^{28}$ they do not need to be intense and prolonged to produce beneficial effect. ${ }^{6,29}$ One possible explanation regarding why positive emotions produce positive changes in individuals and negative emotions (as stressors) evoke negative consequences may be found in physiological reciprocations of positive versus negative emotions. The latter alters our internal milieu to create conditions favorable for illness ${ }^{30}$ and disturbs our equilibrium as well as breaks down our resources, unlike positive emotions. They produce 'Catabolic' changes and we feel unpleasant and distressed. The messages producing positive emotions are processed by our left hemisphere, while the negative emotion producing messages are processed by our right hemisphere due to what is known as "Functional Asymmetry of Brain". ${ }^{31}$ The neuroendocrine stimulation subsequent to experiencing positive emotions stimulates "anabolic" activities in the body and we experience a pleasant state and feel comfortable.

\section{Basics of interpersonal communication}

Now turning to communication we see that it is derived from the Latin Word Communis (a common platform). Communication means exchange of commonly meaningful messages interpersonally, person to group, or group to group. Human beings, through formal and informal socialization, via interaction with environment gradually grow and realize that fulfillment of all needs is impossible without 
mutual interaction and interdependence with, and upon other human beings. Only then, man can exist effectively as a dynamic, living, social entity. Below is presented a model of communication process showing its key ingredients:

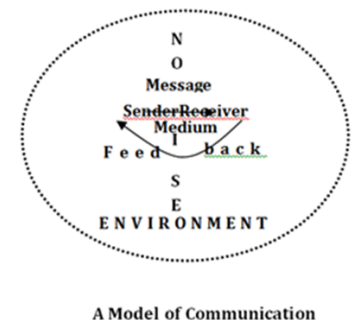

Source: Giffin K, Patton BR (1971) Fundamentals of Interpersonal Communications. Harper \& Row, NY, USA

Non-verbal communication ultimately defines an interpersonal relationship. (Facial Expression, Gesture, Posture, Vision, Gait, Body rhythms are non-verbal communications). ${ }^{32}$ At any given moment the total messages emanated by a human being is $80 \%$ non-verbal and $20 \%$ verbal. $^{15}$ It is the most important point, which a psychologist needs to ponder upon, whenever thinking of helping fellow human beings in trouble. He has to become an 'observer' in the real sense of the term, in order to really understand an individual.

Communication, physical and mental health: In order to be beneficial communication must be positively meaningful to both interact ants (Negative communication is undesirable). Positive communication helps to diffuse the conditions of tension and thereby acts as a preventive agent of mental ill health. Comforting interpersonal contact is very much important for human growth and healthy living.

Therefore, it seems proper to say that positively meaningful communication produces immense satisfaction which is positive emotion and therefore, immensely valuable in promotion of health, happiness and longevity. The reverse is also very much true i.e. when the communication is negatively meaningful it produces negative emotions the impacts of which have already been pointed out.

\section{Why communication becomes negative or breaks down}

The three-thronged goal of psychologists world-wide is to understand, predict and control behaviour so as to enable the individual be happy, productive and positively contributive to self \& Society. It presupposes understanding why communication breaks down.

Communication is sharing of self by revealing self via selfdisclosure. It is the best gift - the gift of love. Giffin \& Paton ${ }^{15}$ identified four distinct areas of such causes in the following way.

Absence of interpersonal trust: A person experiences a trust of another person when he feels that he is psychologically safe in relation to that person. Trust brings two persons close and keeps them close. It develops due to WEG (Warmth, Empathy \& Genuineness). ${ }^{33}$ Sensing absence of psychological safety crumples down the relationship.

Defensive communication: One way of promoting interpersonal trust is not to provoke defensive communication. We defend, we protect ourselves from threat by another person. It prevents progress of healthy relationship formation. Manifest behaviour of the following kinds from person A generates defensive communication in person B..$^{34}$

i. Evaluation/judgment, ii. Controlling communications,

iii. Perception of ulterior motives (hidden motives),

iv. Manifest lack of concern for welfare of the person's concerned,

v. Attitudes of superiority,

vi. Speech with finality,

vii. Making premature comments,

viii. Making statements that are too general or excessively firm,

ix. Interrupting others

$\mathrm{x}$. Repeated disagreements, ${ }^{35}$

xi. Talking too much,

xii. Repeatedly telling others what to do,

xiii. Asking emotionally loaded question,

xiv. Administering punishment through sarcasm,

$\mathrm{xv}$. Blaming or forfeiting (constantly fault finding) behaviour,

xvi. Arguing ${ }^{35}$

xvii. Displaying irritating hearing habits.

Therefore, reducing defensive communication by not resorting to antecedent behaviours and increasing interpersonal trust appear to be extremely valuable goals of effective interpersonal communication.

Gaps between people: Different generation, different cultures (ways of life,) different experiential realities, (most important reason) create gaps between people. Closer we are in terms of psychosocial standards with other person, lesser is the perceived social discomfort and better is the communication.

Alienation: A person is alienated when he/she withdraws from or avoids another person/s (of equal status). When one cannot communicate with another person and withdraws from interactions, alienation has occurred in that person. The individual feels uneasiness or discomfort, which leads to his self-exclusion from social or cultural participation with equals. It is maladjustment.

Ambivalence over emotional expression: Another point seems to be worth mentionable at this juncture. Evanova \& Watson ${ }^{10}$ reported that 'Ambivalence over emotional expression might lead to refraining from emotional expression which can seriously impact an individual's emotional as well as overall wellbeing. It is not expression of emotions in communications that causes adverse consequences, but rather the internal conflict that an individual experiences over expressing emotion (e.g. an individual desirous of expressing affection to someone inhibits that desire. Conversely, he can express an emotion, say lash out in anger and later regrets it). Ambivalent people are overall less expressive. Although they desire to express, they inhibit the desire. Besides having lower self-esteem and overall life satisfaction, they report high scores of depression, daily negative effects, obsessive-compulsive tendencies, paranoid ideation, phobia and anxiety. It renders such individuals more vulnerable emotionally in so far as they find to respond more intensely and take longer time to recover from an emotional event. In a sense, it interupts the normal flow of communication. These findings highlight the importance of ambivalence over emotional expression in personal wellbeing.

Other biases leading to misperception of communication are as follows: 
a. What a person hears or understands when someone speaks to him is largely shaped by his own experiences, background (what he expects to hear)

b. People have different perceptions of the same messages.

c. People evaluate the source- asks question "how reliable is the sender"

d. We ignore information that conflict with what we already know.

e. Our emotional state conditions what we hear when we are aroused, irritated, enraged, in secured, worried, or fearful.

f. We do not know how the other man perceives the situation.

After all however, the negative communication situation is not so hopeless and desperate. It can be improved and good communication can be cultivated.

\section{How to improve communication}

A. Be non-possessive, 'warm', 'empathic' and 'facilitatively genuine' and thereby have a high "Social comfort" level. ${ }^{33,36}$ If they are not already there, they can be cultivated. Warmth is the unconditional respect and acceptance of others as they are. Empathy is experiencing another's reality as ones own. Genuineness is no disparity between thoughts, feelings and behavioural aspects of a person. Rogers ${ }^{33}$ further opined that being genuine must not mean expressing everything that is coming in mind, but expressing only those thoughts and feelings which may not hurt the other person and do not cause communication breakdown i.e. one needs to be 'facilitative genuine'. 'High Social Comfort' of person 'A' means that others will feel comfortable in his presence, as he has high amounts of warmth (W), empathy (E) and facilitative genuineness $(\mathrm{G})$.

B. Utilizing feedback: Now referring back to the feedback portion of the communication process model given earlier in this article, it may be noted there that utilizing feedback, from the receiver by the sender of the message have immense potentials for being a good and effective communicator. They are explored in the following paradigm:

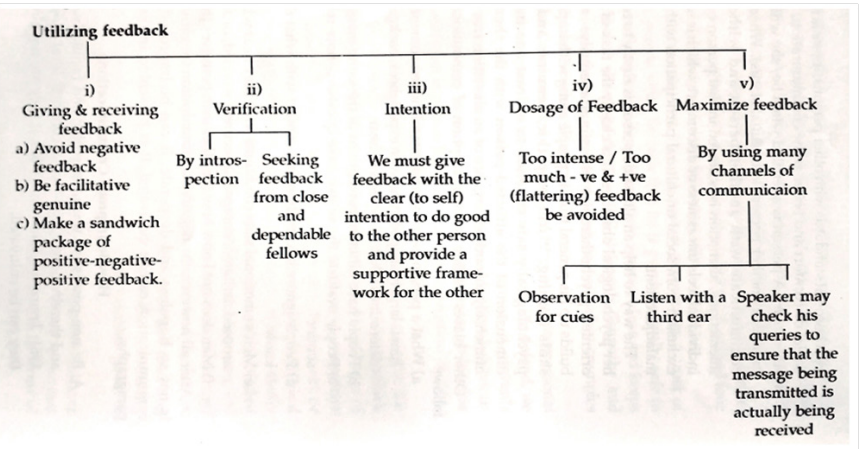

C. Use face to face communication

D. Be sensitive to the world of the receiver

E. Be aware of symbolic meaning

F. Time the messages carefully when noises are least. Lessen the noises as far as possible.

G. Reinforce words with actions.

H. Use direct simple language.

\section{Introduce proper amount of redundancy.}

It would be highly desirable for any human being to be and to remain a good and effective communicator which not only would help him as regards to his total adaptation process but also it is highly likely to benefit the people living in his interpersonal milieu. The following guidelines, laid down by Brady \& Powell, ${ }^{37}$ are likely to help one who wants to be a good communicator:

1. A firm commitment to sharing

2. An attitude that sees ourselves and others as gifts to be given \& received.

3. A relentless honesty with ourselves.

4. Acceptance of personal responsibility for our actions, reactions and lives.

5. A humility that knows that we can tell only our personal truth and that we cannot claim to have the truth.

6. Emotional openness or an honest sharing of all our significant feelings.

7. A willingness to share our own vulnerability.

8. A heart that is grateful to others for their willingness to listen

9. A gift of presence and availability to others.

10. Acceptance of others, whatever they are.

11. Listening to learn the inner consistency of other.

12. The knowledge that we cannot judge others.

13. A gift of empathic reactions to others who are different from ourselves.

14. The effort to understand not just the words but the meaning of what others are saying i.e. to listen with head and heart.

15. Our gift of independence to others by refusing to give advice or to make decisions for them.

16. The clear-sighted courage that overcomes all the blocks to good communication

17. An explicit expression of thanks to those who have trusted us enough to share with us.

18. Faithfulness in spending "quality' or 'Special' time together.

19. Communicating through the sense of touch.

20. Stretching out of our comfort zones.

21. Admitting our failures and apologizing to those we have hurt.

22. Avoiding a buildup of physical tension and negative stress.

23. Dealing effectively and courageously with our communication crisis.

24. Speaking and listening always and only out of love, usually.

25. Consistently praying to God to supply us with the enlightment and courage we need.

\section{Conclusion}

Human beings humanness comes from emotions. Emotions which we like to rejoice are positive emotions. Emotions which go against 
our cores are negative emotions making us to feel bad, angry or sad. They generate from either direct experiences (here and now) or may be the resultant of reappraisals of past experiences (there and then). Positive emotions create genuine good effects upon body and mind of both communicator and communicatee. Not only do they feel good but individuals want to feel them..$^{38}$

Positive emotions enhance resilience or positive adaptation in the midst of adversities. Resilient people use positive emotions to bounce back from negative emotional experiences, can flexibly adapt to changing demands in stressful situation.

Just as water, air and food are essential for physical living of the person, so also same is communication - the lifeblood of mind. Being the chief adhesive agent of bonding people together, it helps people to reach each other, live together meaningfully and adapt to its environment every moment. And it is a very promising process vehicle for enhancing experience of positive emotions every moment of living. Of course, for fullness and richness of human life, experiencing some negative emotions is also necessary, ${ }^{25}$ but they must not outweigh positive emotional experiences in any way.

While communicating with others, hence, a person not only has to have good communication skills, but also she/he needs to be oriented positively about all living creatures on this earth and respect them as creation of god. Because positive emotions generated by interpersonal communication every day not only does transform individuals, but also groups of people in community and organization. Societal transformation may come true because each person's communication can resound through others.

The ray of hope lies in the truth that good communication skills can be learned and positive emotion can be cultivated also indirectly by:

1. Finding positive meaning within current circumstances by finding positivity within adversity,

2. Infusing ordinary events with meaning; and

3. By effective problem solving. . $5,39,40$ both individually and collectively.

Lastly, for the above to achieve, we must have a firm decision to relearn and change ourselves and change is always a little bit scary. Because we know what we have got and we cannot be sure about what we will get. Engaging one's self and helping others to learn positive communication is a matter of attitude, it doesn't require spending money and it does not need using costly equipment. Caring words, listening with all attentions, using a calm tone of voice, softly looking in the eyes, a smile and a genuine concern for well-being of the communicate are all what are needed and attainment of such mental state can be triggered automatically when one thinks about positive and loving thoughts. However, only the golden touch of love for all fellow human beings is most a needed. ${ }^{41-47}$

\section{Acknowledgments}

None.

\section{Conflicts of interest}

Author declares there are no conflicts of interest.

\section{Funding}

None.

\section{References}

1. Kuppens P, Realo A, Diener E. The Role of Positive and Negative Emotions in Life Satisfaction Judgement Across Nations. J Pers Soc Psychol. 2008;95(1):66-75.

2. James W. The Varieties of Religious Experience: A study in Human Nature. Random House, Original Works published in 1902, NY, USA. 2012.

3. Lucas RB, Diener E, Sue E. Discrimination validity of wellbeing measures. J Pers Soc Psychol. 1996;71(3):616-628.

4. Larsen R. The Contribution of Positive and Negative Affects to Emotional Wellbeing. Psychological Topics. 2009;18(2):247-266.

5. Yulimaz H, Arslan C. Subjective Wellbeing, Positive and Negative affects in Turkish University students. The Online Journal of Counselling and Education. 2013;2(2):1-8.

6. Kong F, Zhau Z. Affective mediators of the relationship between Trait Emotional Intelligence and Life Satisfaction in young adults. Personality and Individual Differences. 2013;54(2):197-201.

7. Mukherjee I. Experiencing Positive Emotions: The Gateway to Happy and Long Life. In: Yadav et al. (Eds.), Biopsychosocial issues in Positive Health, Global Vision Publishing House, New Delhi, India. 2021. p.143-152.

8. Erozcan, Atilgan. The Effects of Communicational skills and Interpersonal Problem Solving Skills on Social Self and Efficacy. Educational Sciences: Theory and Practice. 2013;13(2):730-745.

9. McAdams DP. Personal Needs and Personal Relationships. In: Steve Duck (Ed.), Handbook of Personal Relationships, John Wiley and Sons. NY, USA. 1988. p. 7.

10. Euripedes ME, Eryna V, Watson JC. The Role of Emotional Expression in Romantic Relationships. Baltic Journal of Psychology. 2010;11(1,2):62-72.

11. Duck SW. Personality similarity and friendship choices by adolescents. European Journal of Social Psychology. 1975;5(3):351-365.

12. D'Zurilla TI, Nezu AM. Problem Solving Therapy: A social competence approach to clinical intervention. (2nd edn), Springer, NY, USA. 1999.

13. Fredrickson BL. The value of Positive Emotions. American Scientist. 2003;91(4):330-335.

14. Diener Ed, Chan Micaela Y. Happy People Live Longer: Subjective Wellbeing Contributes to Health and Longevity. Health and Wellbeing. 2011;3(1):1-43.

15. Giffin K, Patton BR. Fundamentals of Interpersonal Communications. Harper and Row, NY, USA. 1971.

16. Henderson S. The Social Network Support and Neurosis. Br J Psychiatry. 1977;131:185-191.

17. Butler EA, Sabrra DA.Health, emotions and relationships. Journal of Social and Personal Relationships. 2013;30(2):151-154.

18. Whisman MA. Relationship discord and the prevalence, incidence and treatment of psychopathology. Journal of Social and Personal Relationship. 2013;30(2):163-170.

19. Hecht ML. The conceptualization and measurement of Interpersonal Communication Satisfaction. Human Communication Research. 1978; $4(3): 253-264$

20. Fredrickson BL, Levenson RW. Positive emotions speed recovery from the cardiovascular sequel of negative emotions Cogn Emot. 1998;12(2):191-220.

21. Fredrickson BL, Joiner T. Positive Emotion trigger upward spiral towards Emotional Wellbeing. Psychol Sci. 2002;13(2):172-175. 
22. Duck S. The Personal Context: Intimate relationships. In: Feldman \& Orford (Eds.), Psychological Problems; The Social Context, John Willy and Sons. NY, USA. 1980. p. 73-74.

23. Gibbs J. Climate for Trust Formation. In: Bradford, et al. (Eds.), t-group Theory and Laboratory Method. Innovation in Reeducation, Wiley, NY, USA. 1964. p.279-309.

24. Selye Hans.History of the Present Status of the Stress Concept. In: Leo Goldberger \& Sholmo Braznitz (Eds.), The Handbook of Stress, USA. 1982. p.10.

25. Baumgardner MR, Crothers HF. Positive Psychology, Pearson Education, India. 2009.

26. Fredrickson BL. The Role of Positive Emotions in Positive Psychology. The Broaden and Build Theory of Positive Emotions. Am Psychol. 2001;56(3):218-226.

27. Anila A, Najma IM, Mohsin A. The moderating role of positive and negative emotions in relationship between Positive Psychological Capital and Subjective Well-being among adolescents. International Journal of Research Studies in Psychology. 2014;3(3):29-42.

28. Folkman S. Positive Psychological Status: Coping with severe stress. Soc Sci Med. 1997;45(8):1207-1221.

29. Ibid. Is Resiliency a Skill or an Outcome? presented in a panel discussion in 6th International Conference on Life Skills Education 14th February 2015 at Guahati, Assam, India. 2015.

30. Zegans AL. Stress and development of somatic disorders. In: Leo Goldberger \& Sholmo Berznitz (Eds.), Handbook of Stress, The Free Press, NY, USA. 1982. p.134-152.

31. Sakeim HA, Weber SL. Functional Brain Asymmetry in Regulation of Emotion: Implication for Bodily Manifestation of Stress. In: Leo Goldberger \& Sholmo (Eds.), Handbook of Stress, The Free Press, NY, USA. 1982. p.183-199.

32. Babonea A, Muntenu A. Towards positive interpersonal relationships in the classroom. presented in International Conference on scientific papers, AFASES, Brasov, Romania. 2012.

33. Rogers CR. On becoming a person, Houghton Miffin Co, Boston, USA 1961.

34. Ibid. Interpersonal Communication in developing acquaintance. In: Miller (Ed.), Explorations in Interpersonal Communications, Sage, NY, USA. 1976.
35. Yoder Jan. The effects of disagreement on the continuation of Interpersonal Relationships. Human Relations. 1981;34(3):195-205.

36. Traux CB, Carkhauff R. Toward effective Counselling and Psychotherapy, Chicago, USA. 1967.

37. Brady, Powel SJ. Will the Real Me Please Stand Up? Tabur Publishing Valencia, California, USA. 1985

38. Fredrickson BL. What Good are Positive Emotions. Rev Gen Psychol. 1998;2(3):300-319.

39. Fredrickson BL. Extracting Meaning from Past Affective Experiences: The importance of Peaks, Ends and Specific Emotions. Cognitive and Emotions. 2000;14(4):577-606.

40. Fredrickson BL. Why Positive Emotions Matter in Organisations: Lessons from the Broaden and Build Theory. The Psychologist Manager Journal. 2000;4(2):131-132.

41. Robert Biswas-Diener, Joar Vittersø, Ed Diener. Most People are Pretty Happy, But there is Cultural Variation: The Inugheicts, the Amish and Massai. Journal of Happiness Studies. 2005;6(3):205-226.

42. Ibid. Defensive Communication. Journal of Communication. 1964;11(3):141-148.

43. Ibid. on becoming a counselor, Houghton Miffin Co, Boston, USA 1961.

44. Moscawritz JY. Positive affects predict lower rate of AIDS mortality. Psychosom Med. 2003;65(4):620-626.

45. Nørgaard B, Ammentorp J, Ohm Kyvik K, et al. Communication Skills Training Increases Self-Efficacy of Health Care Professionals. rnl $J$ Contin Educ Health Prof. 2012;32(2):90-97.

46. Ostir GV, Markides KS, Black SA, et al. Emotional Wellbeing Predicts subsequent functional independence and survival. J Am Geriatr Soc. 2000;48(5):473-478.

47. Uchino BA. Understanding the links between social ties and Health: On building stronger bridges with relationship Science. Journal of Social and Personal Relationships. 2013;30(2):155-162. 